\title{
Review Article \\ Obesity and Pulmonary Hypertension: A Review of Pathophysiologic Mechanisms
}

\author{
Scott E. Friedman ${ }^{1,2}$ and Bruce W. Andrus ${ }^{1,2}$ \\ ${ }^{1}$ Section of Cardiology, Heart and Vascular Center, Dartmouth-Hitchcock Medical Center, Lebanon, NH 03756, USA \\ ${ }^{2}$ Department of Medicine, Geisel School of Medicine at Dartmouth, Hanover, NH 03755, USA
}

Correspondence should be addressed to Bruce W. Andrus, bruce.w.andrus@dartmouth.edu

Received 3 March 2012; Accepted 18 July 2012

Academic Editor: David Allison

Copyright ( 92012 S. E. Friedman and B. W. Andrus. This is an open access article distributed under the Creative Commons Attribution License, which permits unrestricted use, distribution, and reproduction in any medium, provided the original work is properly cited.

\begin{abstract}
Pulmonary hypertension $(\mathrm{PH})$ is a potentially life-threatening condition arising from a wide variety of pathophysiologic mechanisms. Effective treatment requires a systematic diagnostic approach to identify all reversible mechanisms. Many of these mechanisms are relevant to those afflicted with obesity. The unique mechanisms of $\mathrm{PH}$ in the obese include obstructive sleep apnea, obesity hypoventilation syndrome, anorexigen use, cardiomyopathy of obesity, and pulmonary thromboembolic disease. Novel mechanisms of $\mathrm{PH}$ in the obese include endothelial dysfunction and hyperuricemia. A wide range of effective therapies exist to mitigate the disability of $\mathrm{PH}$ in the obese.
\end{abstract}

\section{Educational Objectives of the Review}

Obesity and pulmonary hypertension (PH) are two conditions that frequently coexist in clinical practice. In this paper, we will discuss (1) the general approach to the evaluation of pulmonary hypertension, (2) the prevalence of $\mathrm{PH}$ in the obese, (3) the mechanisms by which obesity leads to $\mathrm{PH}$, and (4) the evaluation and treatment of $\mathrm{PH}$ in the obese.

\section{Pulmonary Hypertension}

2.1. Definition. Pulmonary hypertension is formally defined by a mean pulmonary artery pressure exceeding $25 \mathrm{~mm} \mathrm{Hg}$ on right heart catheterization. However, because of its noninvasive nature, echocardiography is commonly used to screen for $\mathrm{PH}$ and provides estimates of peak pulmonary artery systolic pressure (PASP). Unfortunately, there is no reliable echocardiographic method of determining mean pulmonary artery pressure. Rather, echocardiographically determined pulmonary artery systolic pressures greater than $40 \mathrm{~mm} \mathrm{Hg}$ are considered abnormal. A study correlating echocardiographic and invasive hemodynamic findings reported that a PASP greater than $45 \mathrm{~mm} \mathrm{Hg}$ had $97 \%$ specificity for pulmonary hypertension [1]. Notably, the sensitivity was only $47 \%$, highlighting the limitation of echo in excluding pulmonary hypertension. The decision to proceed to invasive evaluation depends on the clinical suspicion, the importance of making the diagnosis, and the risk of the invasive procedure.

2.2. Clinical Symptoms and Signs. Patients with pulmonary hypertension present with symptoms of dyspnea on exertion, fatigue, chest pain, syncope, palpitations, and lower extremity edema [2]. Common exam findings include a sternal lift, loud $\mathrm{P} 2$, right-sided S4, a murmur of tricuspid regurgitation with giant $\mathrm{v}$ waves, and a pulsatile liver [2].

In advanced $\mathrm{PH}$, patients become dyspneic at rest and hypoxic due to severely impaired diffusion capacity. They are prone to chest pain related to RV myocardial oxygen demand outstripping supply and exertional syncope related to failure of the RV to eject against its elevated afterload. Progressive lower extremity edema, liver failure, and ascites also occur due to chronically elevated RA pressure.

2.3. Prevalence of $\mathrm{PH}$ in the General Population. Pulmonary arterial hypertension (PAH), often termed primary pulmonary hypertension, is a relatively rare condition. A French 
TABle 1: Dana Point clinical classification of pulmonary hypertension (2008).

\begin{tabular}{ll}
\hline & $\begin{array}{l}\text { Pulmonary arterial hypertension (PAH). } \\
\text { Examples: idiopathic, familial, drug and toxin induced, collagen vascular disease, congenital left to right shunts, HIV, portal } \\
\text { hypertension, schistosomiasis, chronic hemolytic anemia, pulmonary venoocclusive disease, pulmonary capillary } \\
\text { hemangiomatosis. }\end{array}$ \\
\hline Group 2 & $\begin{array}{l}\text { Pulmonary hypertension owing to left heart disease. } \\
\text { Examples: chronic severe left sided valve disease, left ventricular severe systolic, or diastolic heart failure. }\end{array}$ \\
\hline \multirow{2}{*}{ Group 3} & $\begin{array}{l}\text { Pulmonary hypertension owing to lung diseases and/or hypoxia. } \\
\text { Examples: COPD, interstitial lung disease, sleep-disordered breathing, alveolar hypoventilation, chronic exposure to high } \\
\text { altitudes. }\end{array}$ \\
\hline Group 4 & $\begin{array}{l}\text { Chronic thromboembolic pulmonary hypertension (CTEPH). } \\
\text { Examples: thrombotic obstruction of the pulmonary arteries. }\end{array}$ \\
\hline & $\begin{array}{l}\text { Pulmonary hypertension with unclear multifactorial mechanisms. } \\
\text { Examples: myeloproliferative disorders, splenectomy, sarcoidosis, pulmonary Langerhans cell histiocytosis, } \\
\text { Group } 5\end{array}$ \\
$\begin{array}{l}\text { lymphangioleiomyomatosis, neurofibromatosis, vasculitis, thyroid disease, fibrosing mediastinitis, chronic renal failure on } \\
\text { dialysis, tumor obstruction, glycogen storage disease. }\end{array}$
\end{tabular}

HIV: human immunodeficiency virus, COPD: chronic obstructive pulmonary disease.

registry estimates the prevalence of $\mathrm{PAH}$ at 15 per million adults. Idiopathic $\mathrm{PAH}$ is the most common form of $\mathrm{PAH}$ and is more common in women [3].

The prevalence of $\mathrm{PH}$ is significantly greater when secondary forms of $\mathrm{PH}$ are considered. A survey of residents in Olmstead County, Minnesota found that $25 \%$ had an echo-based estimate of PASP exceeding $30 \mathrm{~mm} \mathrm{Hg}$ [4]. Additionally, the authors found that PA pressure increased with age.

2.4. Classification. Though sometimes referred to as a specific disease, pulmonary hypertension is simply an objective finding, akin to an opacity on a chest radiograph, with a wide variety of underlying causes. Effective treatment requires a more specific diagnosis. In an effort to incorporate evolving evidence, the classification system of $\mathrm{PH}$ has been repeatedly updated since the first WHO conference in 1973 [5]. The most recent classification was established at the 4th WHO World Symposium in 2008 at Dana Point, California. In this schema, $\mathrm{PH}$ is divided into 5 primary categories (Table 1) [6]. They include Group I (pulmonary arterial hypertension), Group II (owing to left heart disease), Group III (owing to lung disease or hypoxemia), Group IV (chronic thromboembolic pulmonary hypertension), and Group V (unclear or multifactorial mechanisms). Group I is distinct as the group which benefits from specific pulmonary vascular remodeling agents including phosphodiesterase 5 inhibitors, endothelin antagonists, and prostacyclin analogs. Group I includes idiopathic PAH, familial PAH, and PAH associated with connective tissue disease, HIV infection, portal hypertension, congenital heart disease, schistosomiasis, chronic hemolytic anemia, pulmonary venoocclusive disease, and pulmonary capillary hemangiomatosis.

2.5. Prognosis. Despite modern therapy, the prognosis of $\mathrm{PAH}$ is poor with a 1-year mortality of $15 \%$ [7]. Adverse prognostic markers include a 6 -minute walk test less than 300 meters, right atrial pressure greater than $20 \mathrm{mmHg}$, right ventricular enlargement or dysfunction, cardiac index less than $2 \mathrm{~L} / \mathrm{min} / \mathrm{m}^{2}$, elevated $\mathrm{BNP}$, and scleroderma spectrum etiology [2].

2.6. Treatment. Optimal treatment hinges on an accurate and specific diagnosis. As noted above, the drugs developed for PAH have been established as safe and efficacious only for PAH (WHO Group I) and may precipitate sudden decompensation in WHO Group II (PH owing to left heart failure). For WHO Groups II-V, the treatment of PH is generally aimed at the underlying disorder supplemented by the treatment of hypoxemia and the judicious use of diuretics and digoxin [8].

\section{Coexistence of Obesity and Pulmonary Hypertension}

3.1. Prevalence of Obesity. Data from the 2007-2008 National Health and Nutrition Examination (NHANES) reveal that over two-thirds of the US adult population is overweight or obese [9]. Tragically, these individuals carry a disproportionate burden of many chronic illness including diabetes, hypertension, coronary disease, heart failure, arthritis, and gall bladder disease [10].

3.2. Prevalence of $P H$ in the Obese. There is limited data on the prevalence of $\mathrm{PH}$ in the obese. A retrospective single center study reported that $5 \%$ of otherwise healthy individuals with a BMI $>30 \mathrm{~kg} / \mathrm{m}^{2}$ had moderate or severe pulmonary hypertension (PASP greater than $50 \mathrm{~mm} \mathrm{Hg}$ on echocardiogram) [11]. The inclusion of lesser severity $\mathrm{PH}$ would likely greatly increase the prevalence. A single center showed that $38 \%$ of patients with primary $\mathrm{PH}$ were obese and $48 \%$ of patients with severe secondary $\mathrm{PH}$ were obese [12]. Finally, a positive relationship between BMI and RV dysfunction (a sequella of chronic pulmonary hypertension) has been described after controlling for age, insulin, and mean arterial pressure [13].

Multiple mechanisms link obesity to pulmonary hypertension and more than one may simultaneously operate in 
an individual patient. Several investigators have suggested a synergistic effect of multiple factors by demonstrating pulmonary hypertension out of proportion to what would be expected based on any of the individual mediators $[14,15]$. In the following section, we review the evidence linking obesity and its comorbidities to pulmonary hypertension.

\section{Specific Pathophysiologic Mechanisms}

4.1. Obstructive Sleep Apnea. Obstructive sleep apnea (OSA) is characterized by obstructive episodes associated with signs of disturbed sleep (e.g. snoring and restlessness) and daytime somnolence. The prevalence of symptomatic obstructive sleep apnea in a middle-aged population is $4-5 \%[16,17]$. Sleep-disordered breathing, defined as $>5$ apneic episodes per hour, is frequent, occurring in nearly one in five adults. Obesity is the strongest risk factor for OSA; this is evidenced by the $40 \%$ prevalence of OSA in the obese [18]. Obstructive sleep apnea was formally recognized as a cause of $\mathrm{PH}$ when the WHO added OSA to the group III classification of PH in 2009 [6]. The prevalence of $\mathrm{PH}$ in patients with OSA varies from $17 \%$ to nearly $50 \%[17,19-21]$. Definitions of $\mathrm{PH}$ and the method of measuring PA pressure (echocardiogram versus right heart catheterization) have varied between studies, and these variations contribute to the wide range in the reported prevalence of $\mathrm{PH}$ in patients with OSA. The largest data set with invasive measurement of pulmonary artery pressures demonstrates a $17 \%$ incidence of $\mathrm{PH}$ in 220 consecutively enrolled OSA patients [22]. Obstructive sleep apnea leads to repetitive nocturnal hypoxemia, hypercapnia, acidosis, increased sympathetic tone, and wide swings of intrathoracic pressure. Endothelial dependent vasoreactivity is also diminished by OSA [23]. These processes lead to pulmonary artery hypoxic vasoconstriction and subsequent pulmonary arteriolar remodeling. Animal models have clearly demonstrated that brief, repetitive exposure to hypoxemia over a duration of just a few weeks is sufficient to cause pulmonary arteriolar remodeling and right ventricular hypertrophy $[24,25]$.

In isolation, OSA typically causes only mild $\mathrm{PH}$ that does not require specific treatment aimed at $\mathrm{PH}[14,21$, 26, 27]. However, OSA patients often present with more severe degrees of $\mathrm{PH}$ when they have comorbid conditions contributing to hypoxemia. These conditions include diastolic heart failure (often due to obesity of cardiomyopathy), restrictive lung disease, COPD, obesity hypoventilation syndrome, and residence at a moderately high altitude $[15,26,28,29]$. Obstructive sleep apnea mediated $\mathrm{PH}$ has downstream effects on the right ventricle. This has been demonstrated in echocardiographic studies showing severe OSA is linked to right ventricular hypertrophy and diminished right ventricular contractility [30-32]. While subtle changes in RV morphology and function are common in the obese and those with OSA, end stage right heart failure, cor pulmonale, is not typically caused by OSA alone [13].

The strongest evidence for OSA as an independent cause of $\mathrm{PH}$ comes from studies showing that treatment of OSA with continuous positive airway pressure (CPAP) lowers pulmonary artery pressures. CPAP ameliorates $\mathrm{PH}$ by correcting hypoxia and acidosis, lowering sympathetic tone and improving endothelial function $[33,34]$. Arias et al. used a placebo-controlled, crossover design in randomizing OSA patients and normal controls to CPAP or sham CPAP for 12 weeks [29]. Effective CPAP resulted in a statistically significantly drop in pulmonary artery systolic pressure. In an earlier study, six months of CPAP therapy in patients with OSA and $\mathrm{PH}$ yielded a small, but statistically significant $3 \mathrm{mmHg}$ drop in mean PA pressures. The drop in PA pressure with treatment of OSA strongly points to OSA as an independent and causative mediator of $\mathrm{PH}$. However, most patients in these studies had only mild PH. Further, CPAP resulted in a relatively small, albeit statistically significant, drop in PA pressures. Further study is needed to determine if CPAP leads to clinically relevant improvements in functional status or outcome in $\mathrm{PH}$ patients with OSA.

In sum, OSA has emerged as an independent risk factor for PH. Treatment of OSA with CPAP modestly improves pulmonary artery pressures. Isolated OSA typically results in only mild $\mathrm{PH}$, but when OSA is combined with a second cause of hypoxemia, $\mathrm{PH}$ can be moderate or severe.

4.2. Obesity Hypoventilation Syndrome. Obesity hypoventilation syndrome (OHS) is defined by chronic hypoventilation and hypoxemia in the obese patient with sleepdisordered breathing. The prevalence of OHS and its severity are linearly related to BMI. Obesity hypoventilation syndrome is very rare at BMI less than $30 \mathrm{~kg} / \mathrm{m}^{2}$ but occurs in $31 \%$ of patients with BMI $>35 \mathrm{~kg} / \mathrm{m}^{2}$ [35]. By definition, OHS is associated with diurnal hypoxemia in contrast to the almost exclusively nocturnal hypoxemia seen in OSA. Pulmonary hypertension is more frequent and more severe in OHS as compared to OSA. Pulmonary hypertension occurs in approximately $50 \%$ of OHS patients, as compared to approximately $20 \%$ of OSA patients [17, 36, 37]. The diurnal hypoxemia, hypercapnia, and acidosis associated with $\mathrm{OHS}$ are mediators of PH. Secondary contributors to $\mathrm{PH}$ in patients with $\mathrm{OHS}$ are restrictive lung disease related to severe obesity and the wide intrathoracic pressure shifts in the respiratory cycle due to increased upper airway resistance. Upper airway obstruction results in profound negative intrathoracic pressures during inspiration, up to $-70 \mathrm{~mm} \mathrm{Hg}$. These negative intrathoracic pressures augment RV filling causing a leftward shift of the intraventricular septum which impedes LV filling and thus elevates pulmonary venous pressures and lowers LV stroke volume. This mechanism accounts for the presence of pulsus paradoxus in patients with OHS and severe lung disease.

The pulmonary vascular beds initial response to hypoxemia is vasoconstriction at the pulmonary arteriolar and capillary level. With relief of the hypoxemia this vasoconstriction is reversible. However with chronic hypoxemia, as seen in OHS, pulmonary artery remodeling occurs, and over time the pulmonary arterial hypertension transitions from a process of vasoconstriction to one of endothelial dysfunction, arterial wall thickening, and fibrosis. At this point the $\mathrm{PH}$ becomes much more difficult to reverse.

As mentioned previously, OHS is associated with more severe $\mathrm{PH}$ than is OSA. A small study examining 26 patients 
with OHS compared to the same number of patients with OSA showed the OSH patients were significantly more likely to suffer cor pulmonale (odds ratio of 9, CI 1.457.1) [38]. Treatment of OHS with CPAP is effective in remedying hypoxemia and hypercapnia [28]. As such, it can be presumed that CPAP will improve $\mathrm{PH}$ in patients who have reversible pulmonary hypertension, meaning patients who have not developed pulmonary arteriolar remodeling as a result of the chronic hypoxia. Several small nonrandomized studies suggest CPAP does improve PH [39]. Bariatric surgery and tracheostomy are effective treatments for OHS which improve hypoxemia and hypercapnia [37, 40, 41]. The effect of these treatments on $\mathrm{PH}$ has not been explicitly studied.

4.3. Anorexigen Use. There have been two epidemics of WHO group I (primary) pulmonary hypertension related to anorexigen use. The first occurred in the late 1960s and was associated with the amphetamine analogue aminorex. This drug was strongly linked to primary pulmonary hypertension; the odds ratio for development of primary $\mathrm{PH}$ in patients exposed to this drug was in excess of 1000 [42]. The drug was withdrawn from the market in 1973. The methamphetamine analogues fenfluramine and dexfenfluramine were linked to $\mathrm{PH}$ in the International Primary Pulmonary Hypertension Study (IPPS) published in 1996. In this study, use of anorectic drugs (primarily fenfluramine and dexfenfluramine) was associated with a sixfold increase in the risk of primary $\mathrm{PH}$ [43]. The IPPS data showed the duration of anorexigen use was directly related to the risk of PH. Further studies have confirmed the association of aminorex, fenfluramine, and dexfenfluramine with $\mathrm{PH}$. The $\mathrm{PH}$ associated with anorexigen use is not typically reversible with removal of the drug. The course of $\mathrm{PH}$ associated with anorexigen use is akin to that of the broader population with primary $\mathrm{PH}$ [44]. Fenfluramine and dexfenfluramine are also associated with acquired cardiac valvular pathology and cardiac fibrosis and were withdrawn from the market in 1997. The mechanisms by which these anorexigens precipitate $\mathrm{PH}$ are emerging. Aminorex, fenfluramine, and dexfenfluramine all inhibit a specific membrane potassium channel. The inhibition of this potassium current leads to opening of an L-type calcium channel which has been shown to cause vasoconstriction of the pulmonary arterioles [42]. A second mechanism linking $\mathrm{PH}$ to these drugs involves excess serotonin. These anorexigens increase 5-HT release from platelets. 5-HT, a precursor of serotonin, is a pulmonary vasoconstrictor and mediator of smooth muscle proliferation. Levels of 5-HT are elevated in all Group I PH patients, not just those who have anorexigen exposure [45]. A "serotonin hypothesis" of pulmonary arterial hypertension has evolved based on the lessons learned from the anorexigens and is an area of active research $[45,46]$. There are sporadic case reports of phentermine mediated primary $\mathrm{PH}$; interestingly this drug is shown to inhibit reuptake of 5-HT in a rabbit model. However, to date there is no substantive link between this drug and $\mathrm{PH}$, and this drug remains on the market.
4.4. Cardiomyopathy of Obesity. Obesity is a well-established risk factor for the development of heart failure with obesity, increasing the risk of incident congestive heart failure by two-fold or more $[47,48]$. The cardiomyopathy of obesity is a clinical syndrome characterized by eccentric ventricular hypertrophy (dilation without wall thickening) and diastolic heart failure in severely obese patients [49]. The chronically elevated left ventricular filling pressures associated with left ventricular failure can lead to "secondary" $\mathrm{PH}$. When $\mathrm{PH}$ develops due to this mechanism, it is classified as WHO group II. Initially, elevated left ventricular diastolic pressure is transmitted into the pulmonary venous system elevating pulmonary venous pressure which results in only mild $\mathrm{PH}$, which is typically reversible. However, over time chronically elevated pulmonary venous pressures lead to pulmonary arteriolar remodeling and fixed elevated pulmonary vascular resistance [50].

There are two primary mechanisms postulated to explain the cardiomyopathy of obesity. First, triglyceride excess and mishandling lead to their deposition in myocardial cells, which, in turn, leads to myocardial cell apoptosis and fibrosis [51, 52]. Obese Zucker diabetic fatty rats develop left ventricular dilation and reduced contractility due to steatosis-induced apoptosis of myocardial cells [53]. Further, sulfonylurea therapy lowers myocardial triglyceride levels in these rats and prevents deterioration in myocardial function. Obese diabetic patients have increased myocardial uptake and utilization of nonesterified fatty acids with concomitant decrease in myocardial glucose uptake [54]. These metabolic alterations result in triglyceride and free fatty acid deposition in the myocardium. Myocardial steatosis, visualized on cardiac MRI, is an independent predictor of left ventricular diastolic dysfunction [51]. There is evidence suggesting that the myocardial steatosis process is similar to the more commonly recognized hepatic steatosis, "fatty liver." In fact, elevated liver triglyceride content in type II diabetics is associated with a shift in myocardial metabolism away from glucose towards fatty acids and resultant diastolic dysfunction [55]. Other contributors to myocardial dysfunction in this condition include insulin resistance, elevated sympathetic tone, activation of the renin angiotensin axis, and endothelial dysfunction [56].

The second mechanism by which the obesity of cardiomyopathy begets $\mathrm{PH}$ begins with the physiologic response to the excess volume load placed on the left ventricle in severely obese patients. Intravascular volume expands with obesity. Metabolically active fat requires blood flow leading to higher cardiac output. The increased volume load on the heart also leads to eccentric left ventricular hypertrophy [57]. This change in ventricular morphology is adaptive in its initial stages. Eccentric ventricular hypertrophy is seen with other chronic volume load states such as aortic insufficiency, mitral regurgitation, and atrial septal defects. However, over time the left ventricular dilation becomes pathologic. The initial functional abnormalities are impaired left ventricular diastolic filling and subtle changes in ventricular contractility $[13,58,59]$. Diastolic dysfunction leads to elevated left atrial filling pressures which are transmitted to the pulmonary venous system. Long standing elevation 
in pulmonary venous pressures leads to secondary changes in pulmonary vascular resistance leading to pulmonary hypertension. There is interplay between OSA, metabolic syndrome, and elevated left ventricular filling in the genesis of $\mathrm{PH}$ in some obese patients. This is evidenced by a study showing the majority of OSA patients with coexisting $\mathrm{PH}$ also had elevated left ventricular filling pressures [15, 27]. There appears to be an overlap syndrome where OSA, diastolic heart failure, and metabolic syndrome combine to produce $\mathrm{PH}$ out of proportion to what would be expected from any of the individual conditions $[15,27,29]$. Other contributors to left ventricular myocardial dysfunction in the obese include insulin resistance, elevated sympathetic tone, activation of the renin angiotensin axis, and endothelial dysfunction [56].

The most effective and durable treatment for cardiomyopathy of obesity is weight loss [56]. Weight loss by any means, including diet, exercise, and bariatric surgery, has been shown to improve ventricular function in patients with cardiomyopathy of obesity $[56,60,61]$. Weight loss of only 5 pounds improves left ventricular contractility, diastolic function, and endothelial function [61]. The means by which weight loss is achieved seems to impact the improvement in cardiac function. Wirth and Kroger found that weight loss achieved through diet and exercise resulted in more significant regression of eccentric hypertrophy than did weight loss achieved with diet alone [60]. The effects of pharmacologically induced weight loss on the cardiomyopathy of obesity have not been well documented. There is little other proven treatment for cardiomyopathy of obesity [56].

4.5. Chronic Thromboembolic Disease. Chronic thromboembolic pulmonary hypertension (CTEPH), WHO group IV, occurs in approximately $4 \%$ of patients surviving an acute $\mathrm{PE}$ [62]. The prevalence of the CTEPH in the general population and in the obese is not well characterized [63]. Obesity and insulin resistance are independent risk factors for both deep venous thrombosis and pulmonary embolism [64-66]. Thus, it seems reasonable to speculate that the obese shoulder a disproportionate burden of CTEPH. Sedentary lifestyle and chronic low grade inflammation are long recognized links between obesity and venous thrombi. Obstructive sleep apnea leads to a prothrombotic state via up regulation of platelet aggregation, increased clotting factor activity, and endothelial dysfunction [67-69]. In the acute setting, pulmonary embolus causes $\mathrm{PH}$ through the hemodynamic effects of the embolus lodging in the pulmonary arterial tree. Chronically, there is distortion of the pulmonary vessels due to parenchymal changes and smooth muscle hypertrophy.

4.6. Novel Mechanisms. The role of obesity-induced endothelial dysfunction and oxidative stress in pulmonary hypertension is under active investigation. Insulin resistance is an independent risk factor for $\mathrm{PH}[70,71]$. Obesity, insulin resistance, and sleep apnea have all been shown to impair endothelial function $[33,66,70,72,73]$. These conditions activate vasoconstrictive agents, such as endothelin, and decrease vasodilators, such as nitric oxide which likely accounts for their association with PH. Obesity and its comorbidities are also associated with increased oxidative stress through lipid peroxidation, production of reactive oxygen species, and overexpression of xanthine oxidase [74]. Isolated pulmonary arteries of insulin resistant rats show diminished acetylcholine-mediated nitric oxide release, as well as upregulation of NADPH oxidase, 5-HT, and cycloxygenase-2 proteins [75-77]. Interestingly, in animal models, insulin resistance coupled with moderate hypoxia results in $\mathrm{PH}$ and right ventricular hypertrophy while neither insulin resistance nor hypoxemia alone induces $\mathrm{PH}$ or right ventricular hypertrophy [78]. Treatment with insulin sensitizing agents can reverse $\mathrm{PH}$ and attenuate pulmonary artery remodeling in insulin-resistant rodents [79, 80]. In humans, treatment of OSA with CPAP both lowers PA pressures and improves measures of endothelial function [23, 81, 82]. Insulin-sensitizing drugs improve endothelial function in adults with type II diabetes but the significance of these findings for the pulmonary vasculature has not been defined [83-86].

Hyperuricemia is common in both primary and secondary forms of pulmonary hypertension, and the severity of PH correlates with levels of uric acid [87]. Zharikov et al. have proposed that hyperuricemia is a pathologic mediator of $\mathrm{PH}$ rather than a secondary phenomenon [88]. Chronic hyperuricemia is associated with increased levels of endothelin, diminished nitric oxide production and diminished flow mediated dilation, all markers of endothelial dysfunction $[89,90]$. Diabetes, obesity, and metabolic syndrome may lead to pulmonary hypertension through a mechanism involving hyperuricemia. Lowering uric acid levels to treat $\mathrm{PH}$ has not been fully investigated.

\section{Evaluation and Treatment of Pulmonary Hypertension in the Obese}

5.1. Diagnostic Approach. In this paper, we have highlighted the pathophysiologic mechanisms of pulmonary hypertension in the obese. However, patients with obesity may have any of the recognized forms of pulmonary hypertension mentioned in the classification system previously and should be evaluated in the same systematic fashion as nonobese patients. Due to the numerous and diverse conditions which may underlie pulmonary hypertension, the diagnostic evaluation is extensive. Depending on the proximity of a pulmonary hypertension center, a generalist physician may choose to obtain these studies locally prior to referring the patient. After a careful history, exam, chest X-ray, ECG, and transthoracic echocardiography, the essential tests include a V/Q scan, PFTs, overnight oximetry, HIV screening, antinuclear antibodies, liver function tests, a 6-minute walk test, and a right heart catheterization (extended to left heart catheterization if there is doubt about the veracity of the PCWP and coronary angiography if there is uncertainty about the presence of obstructive coronary disease contributing to dyspnea and exercise intolerance) [2]. Additional studies may be necessary based on these findings, but these studies will generally allow classification and guide 
subsequent treatment decisions. Relevant to obesity, right heart access from an arm vein and left heart access from the radial artery may be preferred.

5.2. Staging of Disease. In addition to determining the etiology of the $\mathrm{PH}$, staging is required to tailor the intensity of therapy. This generally includes a judgment regarding functional class (I-IV), the 6-minute walk distance (in meters), consideration of invasive hemodynamics (RA pressure, mean PA pressure, PVR, and cardiac output), and presence of RV dilation and systolic dysfunction by echocardiography.

5.3. Treatment. A detailed discussion of the treatment of pulmonary hypertension is beyond the scope of this paper, but specific medical therapy is generally limited to those with WHO Group I pulmonary hypertension (pulmonary arterial hypertension) [91]. Drugs from 3 pharmacologic classes (phospodiesterase-5 inhibitors, endothelin receptor antagonists, and prostanoids) delivered by oral, inhaled, continuous subcutaneous, and continuous intravenous routes are approved by the FDA for treatment of pulmonary arterial hypertension. These agents have been shown to improve symptoms and functional capacity, but evidence of mortality benefit is limited to IV epoprostenol [92].

The medical treatment of Groups II-V has not been the subject of many published clinical trials to date, but in general, Group I agents have not been effective in Groups II-IV [93]. In Group II (left heart failure), treatment is generally directed at the underlying cause of the left heart failure and reducing pulmonary venous pressure. Specific to obesity, therapy directed at improving diastolic function is paramount. As noted previously, weight loss by lifestyle and surgical means has been shown to improve diastolic function $[60,61]$. A recent small study has suggested that sildenafil may be effective in the treatment of pulmonary hypertension associated with heart failure with preserved LV function [94]. This needs to be confirmed in a larger trial before widespread adoption. In Group III (chronic lung disease), issues specifically relevant to the obese include treatment of obstructive sleep apnea with weight loss and CPAP and treatment of obesity hypoventilation syndrome with consideration of tracheostomy. In Group IV (chronic thromboembolic disease), evaluation for pulmonary endarterectomy at a specialized center should be considered [95].

\section{Conclusion}

Pulmonary hypertension should be considered in the evaluation of dyspnea in patients with obesity. If elevated pulmonary pressures are documented by echocardiography, further investigations are needed to refine the diagnosis and guide the choice of therapy. Patients with obesity may suffer from any of the etiologies which affect nonobese patients but are at increased risk for obstructive sleep apnea, obesity hypoventilation syndrome, cardiomyopathy of obesity, restrictive lung disease, chronic thromboembolism, and anorexigen-related pulmonary hypertension. In addition, there may be additional mechanisms which are still under investigation. Optimal treatment hinges on an accurate and specific diagnosis. Drugs approved by the FDA for treatment of $\mathrm{PH}$ are limited to Group I PH. Weight loss by a variety of means has been shown to be effective in reducing pulmonary artery pressure and improving cardiovascular function.

\section{Abbreviations}

BMI: Body mass index

CPAP: Continuous positive airway pressure

CTEPH: Chronic thromboembolic pulmonary hypertension

ECG: Electrocardiogram

OHS: Obesity hypoventilation syndrome

OSA: Obstructive sleep apnea

PAH: Pulmonary arterial hypertension

PCWP: Pulmonary capillary wedge pressure

PH: $\quad$ Pulmonary hypertension

PVH: Pulmonary venous hypertension

V/Q: Ventilation and perfusion scintigraphy.

\section{References}

[1] D. Mukerjee, D. S. George, C. Knight et al., "Echocardiography and pulmonary function as screening tests for pulmonary arterial hypertension in systemic sclerosis," Rheumatology, vol. 43, no. 4, pp. 461-466, 2004.

[2] V. V. McLaughlin, S. L. Archer, D. B. Badesch et al., "ACCF/AHA 2009 expert consensus document on pulmonary hypertension a report of the american college of cardiology foundation task force on expert consensus documents and the american heart association developed in collaboration with the american college of chest physicians; american thoracic society, inc.; and the pulmonary hypertension association," Journal of the American College of Cardiology, vol. 53, no. 17, pp. 1573-1619, 2009.

[3] M. Humbert, O. Sitbon, A. Chaouat et al., "Pulmonary arterial hypertension in France: results from a national registry," American Journal of Respiratory and Critical Care Medicine, vol. 173, no. 9, pp. 1023-1030, 2006.

[4] C. S. Lam, B. A. Borlaug, G. C. Kane, F. T. Enders, R. J. Rodeheffer, and M. M. Redfield, "Age-associated increases in pulmonary artery systolic pressure in the general population," Circulation, vol. 119, no. 20, pp. 2663-2670, 2009.

[5] S. Hatano and R. Strasser, Eds., "Primary pulmonary hypertension," World Heath Organization, Geneva, Switzerland, 1975.

[6] G. Simonneau, I. M. Robbins, M. Beghetti et al., "Updated clinical classification of pulmonary hypertension," Journal of the American College of Cardiology, vol. 54, no. 1, supplement, pp. S43-S54, 2009.

[7] T. Thenappan, S. J. Shah, S. Rich, and M. Gomberg-Maitland, "A USA-based registry for pulmonary arterial hypertension: 1982-2006," European Respiratory Journal, vol. 30, no. 6, pp. 1103-1110, 2007.

[8] M. M. Hoeper, J. A. Barberà, R. N. Channick et al., "Diagnosis, assessment, and treatment of non-pulmonary arterial hypertension pulmonary hypertension," Journal of the American College of Cardiology, vol. 54, no. 1, supplement, pp. S85-S96, 2009.

[9] C. L. Ogden, M. D. Carroll, B. K. Kit, and K. M. Flegal, "Prevalence of obesity and trends in body mass index among 
US children and adolescents, 1999-2010," The Journal of the American Medical Association, vol. 307, no. 5, pp. 483-490, 2012.

[10] A. E. Field, E. H. Coakley, A. Must et al., "Impact of overweight on the risk of developing common chronic diseases during a 10-year period," Archives of Internal Medicine, vol. 161, no. 13, pp. 1581-1586, 2001.

[11] B. M. McQuillan, M. H. Picard, M. Leavitt, and A. E. Weyman, "Clinical correlates and reference intervals for pulmonary artery systolic pressure among echocardiographically normal subjects," Circulation, vol. 104, no. 23, pp. 2797-2802, 2001.

[12] A. Taraseviciute and N. F. Voelkel, "Severe pulmonary hypertension in postmenopausal obese women," European Journal of Medical Research, vol. 11, no. 5, pp. 198-202, 2006.

[13] C. Y. Wong, T. O’Moore-Sullivan, R. Leano, C. Hukins, C. Jenkins, and T. H. Marwick, "Association of subclinical right ventricular dysfunction with obesity," Journal of the American College of Cardiology, vol. 47, no. 3, pp. 611-616, 2006.

[14] C. S. Dela Cruz and R. A. Matthay, "Role of obesity in cardiomyopathy and pulmonary hypertension," Clinics in Chest Medicine, vol. 30, no. 3, pp. 509-523, 2009.

[15] C. C. Leung, V. Moondra, E. Catherwood, and B. W. Andrus, "Prevalence and risk factors of pulmonary hypertension in patients with elevated pulmonary venous pressure and preserved ejection fraction," American Journal of Cardiology, vol. 106, no. 2, pp. 284-286, 2010.

[16] V. K. Somers, D. P. White, R. Amin et al., "Sleep apnea and cardiovascular disease: An American Heart Association/american college of cardiology foundation scientific statement from the american heart association council for high blood pressure research professional education committee, council on clinical cardiology, stroke council, and council on cardiovascular nursing. in collaboration with the national heart, lung, and blood institute national center on sleep disorders research (National Institutes of Health)," Circulation, vol. 118, no. 10, pp. 1080-1111, 2008.

[17] C. W. Atwood Jr., D. McCrory, J. G. Garcia, S. H. Abman, and G. S. Ahearn, "Pulmonary artery hypertension and sleepdisordered breathing: ACCP evidence-based clinical practice guidelines," Chest, vol. 126, no. 1, supplement, pp. 72S-77S, 2004.

[18] A. N. Vgontzas, T. L. Tan, E. O. Bixler, L. F. Martin, D. Shubert, and A. Kales, "Sleep apnea and sleep disruption in obese patients," Archives of Internal Medicine, vol. 154, no. 15, pp. 1705-1711, 1994.

[19] E. Bady, A. Achkar, S. Pascal, E. Orvoen-Frija, and J. P. Laaban, "Pulmonary arterial hypertension in patients with sleep apnoea syndrome," Thorax, vol. 55, no. 11, pp. 934-939, 2000.

[20] D. Sajkov, T. Wang, N. A. Saunders, A. J. Bune, A. M. Neill, and R. D. McEvoy, "Daytime pulmonary hemodynamics in patients with obstructive sleep apnea without lung disease," American Journal of Respiratory and Critical Care Medicine, vol. 159, no. 5, part 1, pp. 1518-1526, 1999.

[21] D. Sajkov and R. D. McEvoy, "Obstructive sleep apnea and pulmonary hypertension," Progress in Cardiovascular Diseases, vol. 51, no. 5, pp. 363-370, 2009.

[22] A. Chaouat, E. Weitzenblum, J. Krieger, M. Oswald, and R. Kessler, "Pulmonary hemodynamics in the obstructive sleep apnea syndrome. Results in 220 consecutive patients," Chest, vol. 109, no. 2, pp. 380-386, 1996.

[23] M. Kato, P. Roberts-Thomson, B. G. Phillips et al., "Impairment of endothelium-dependent vasodilation of resistance vessels in patients with obstructive sleep apnea," Circulation, vol. 102, no. 21, pp. 2607-2610, 2000.

[24] M. J. Campen, L. A. Shimoda, and C. P. O’Donnell, “Acute and chronic cardiovascular effects of intermittent hypoxia in C57BL/6J mice," Journal of Applied Physiology, vol. 99, no. 5, pp. 2028-2035, 2005.

[25] M. McGuire and A. Bradford, "Chronic intermittent hypercapnic hypoxia increases pulmonary arterial pressure and haematocrit in rats," European Respiratory Journal, vol. 18, no. 2, pp. 279-285, 2001.

[26] M. Valencia-Flores, V. Rebollar, V. Santiago et al., "Prevalence of pulmonary hypertension and its association with respiratory disturbances in obese patients living at moderately high altitude," International Journal of Obesity, vol. 28, no. 9, pp. 1174-1180, 2004.

[27] O. A. Minai, B. Ricaurte, R. Kaw et al., "Frequency and impact of pulmonary hypertension in patients with obstructive sleep apnea syndrome," American Journal of Cardiology, vol. 104, no. 9, pp. 1300-1306, 2009.

[28] B. Mokhlesi, "Obesity hypoventilation syndrome: a state-ofthe-art review," Respiratory Care, vol. 55, no. 10, pp. 13471362, 2010.

[29] M. A. Arias, F. García-Río, A. Alonso-Fernández, I. Martínez, and J. Villamor, "Pulmonary hypertension in obstructive sleep apnoea: effects of continuous positive airway pressure: a randomized, controlled cross-over study," European Heart Journal, vol. 27, no. 9, pp. 1106-1113, 2006.

[30] U. C. Guidry, L. A. Mendes, J. C. Evans et al., "Echocardiographic features of the right heart in sleep-disordered breathing: The Framingham Heart Study," American Journal of Respiratory and Critical Care Medicine, vol. 164, no. 6, pp. 933-938, 2001.

[31] N. Dursunoğlu, D. Dursunoğlu, and M. Kiliç, "Impact of obstructive sleep apnea on right ventricular global function: sleep apnea and myocardial performance index," Respiration, vol. 72, no. 3, pp. 278-284, 2005.

[32] A. Romero-Corral, V. K. Somers, P. A. Pellikka et al., "Decreased right and left ventricular myocardial performance in obstructive sleep apnea," Chest, vol. 132, no. 6, pp. 1863-1870, 2007.

[33] R. Budhiraja, S. Parthasarathy, and S. F. Quan, "Endothelial dysfunction in obstructive sleep apnea," Journal of Clinical Sleep Medicine, vol. 3, no. 4, pp. 409-415, 2007.

[34] A. A. El-Solh, M. E. Akinnusi, B. Moitheennazima, L. Ayyar, and S. Relia, "Endothelial function in patients with post-CPAP residual sleepiness," Journal of Clinical Sleep Medicine, vol. 6, no. 3, pp. 251-255, 2010.

[35] S. Nowbar, K. M. Burkart, R. Gonzales et al., "Obesity-associated hypoventilation in hospitalized patients: prevalence, effects, and outcome," American Journal of Medicine, vol. 116, no. 1, pp. 1-7, 2004.

[36] R. Kessler, A. Chaouat, E. Weitzenblum et al., "Pulmonary hypertension in the obstructive sleep apnoea syndrome: prevalence, causes and therapeutic consequences," European Respiratory Journal, vol. 9, no. 4, pp. 787-794, 1996.

[37] H. J. Sugerman, P. L. Baron, R. P. Fairman, C. R. Evans, and G. W. Vetrovec, "Hemodynamic dysfunction in obesity hypoventilation syndrome and the effects of treatment with surgically induced weight loss," Annals of Surgery, vol. 207, no. 5, pp. 604-613, 1988.

[38] G. Berg, K. Delaive, J. Manfreda, R. Walld, and M. H. Kryger, "The use of health-care resources in obesity-hypoventilation syndrome," Chest, vol. 120, no. 2, pp. 377-383, 2001. 
[39] J. F. Masa, B. R. Celli, J. A. Riesco, M. Hernández, J. Sánchez de Cos, and C. Disdier, "The obesity hypoventilation syndrome can be treated with noninvasive mechanical ventilation," Chest, vol. 119, no. 4, pp. 1102-1107, 2001.

[40] K. L. Haines, L. G. Nelson, R. Gonzalez et al., "Objective evidence that bariatric surgery improves obesity-related obstructive sleep apnea," Surgery, vol. 141, no. 3, pp. 354-358, 2007.

[41] H. J. Sugerman, R. P. Fairman, R. K. Sood, K. Engle, L. Wolfe, and J. M. Kellum, "Long-term effects of gastric surgery for treating respiratory insufficiency of obesity," American Journal of Clinical Nutrition, vol. 55, no. 2, supplement, pp. 597S601S, 1992.

[42] E. D. Michelakis and E. K. Weir, "Anorectic drugs and pulmonary hypertension from the bedside to the bench," American Journal of the Medical Sciences, vol. 321, no. 4, pp. 292-299, 2001.

[43] L. Abenhaim, Y. Moride, F. Brenot et al., "Appetite-suppressant drugs and the risk of primary pulmonary hypertension. International Primary Pulmonary Hypertension Study Group," The New England Journal of Medicine, vol. 335, no. 9, pp. 609-616, 1996.

[44] R. Souza, M. Humbert, B. Sztrymf et al., "Pulmonary arterial hypertension associated with fenfluramine exposure: report of 109 cases," European Respiratory Journal, vol. 31, no. 2, pp. 343-348, 2008.

[45] M. R. MacLean, "Pulmonary hypertension, anorexigens and 5-HT: pharmacological synergism in action?" Trends in Pharmacological Sciences, vol. 20, no. 12, pp. 490-495, 1999.

[46] M. R. MacLean and Y. Dempsie, "Serotonin and pulmonary hypertension-from bench to bedside?" Current Opinion in Pharmacology, vol. 9, no. 3, pp. 281-286, 2009.

[47] S. A. Hunt, "American College of Cardiology, American Heart Association Task Force on Practice Guidelines (Writing Committee to Update the 2001 Guidelines for the Evaluation and Management of Heart Failure). ACC/AHA 2005 guideline update for the diagnosis and management of chronic heart failure in the adult: a report of the american college of Cardiology/American heart association task force on practice guidelines (writing committee to update the 2001 guidelines for the evaluation and management of heart failure)," Journal of the American College of Cardiology, vol. 46, no. 6, pp. e1-e82, 2005.

[48] S. Kenchaiah, J. C. Evans, D. Levy et al., "Obesity and the risk of heart failure," The New England Journal of Medicine, vol. 347, no. 5, pp. 305-313, 2002.

[49] C. Y. Wong, T. O’Moore-Sullivan, R. Leano, N. Byrne, E. Beller, and T. H. Marwick, "Alterations of left ventricular myocardial characteristics associated with obesity," Circulation, vol. 110, no. 19, pp. 3081-3087, 2004.

[50] V. F. Segers, D. L. Brutsaert, and G. W. De Keulenaer, "Pulmonary hypertension and right heart failure in heart failure with preserved left ventricular ejection fraction: pathophysiology and natural history," Current Opinion in Cardiology, vol. 27, no. 3, pp. 273-280, 2012.

[51] L. J. Rijzewijk, R. W. van der Meer, J. W. Smit et al., "Myocardial steatosis is an independent predictor of diastolic dysfunction in type 2 diabetes mellitus," Journal of the American College of Cardiology, vol. 52, no. 22, pp. 1793-1799, 2008.

[52] C. Wong and T. H. Marwick, "Obesity cardiomyopathy: pathogenesis and pathophysiology," Nature Clinical Practice Cardiovascular Medicine, vol. 4, no. 8, pp. 436-443, 2007.
[53] Y. T. Zhou, P. Grayburn, A. Karim et al., "Lipotoxic heart disease in obese rats: implications for human obesity," Proceedings of the National Academy of Sciences of the United States of America, vol. 97, no. 4, pp. 1784-1789, 2000.

[54] L. J. Rijzewijk, R. W. van der Meer, H. J. Lamb et al., “Altered myocardial substrate metabolism and decreased diastolic function in nonischemic human diabetic cardiomyopathy: studies with cardiac positron emission tomography and magnetic resonance imaging," Journal of the American College of Cardiology, vol. 54, no. 16, pp. 1524-1532, 2009.

[55] L. J. Rijzewijk, J. T. Jonker, R. W. van der Meer et al., "Effects of hepatic triglyceride content on myocardial metabolism in type 2 diabetes," Journal of the American College of Cardiology, vol. 56, no. 3, pp. 225-233, 2010.

[56] C. Wong and T. H. Marwick, "Obesity cardiomyopathy: diagnosis and therapeutic implications," Nature Clinical Practice Cardiovascular Medicine, vol. 4, no. 9, pp. 480-490, 2007.

[57] M. A. Alpert, "Obesity cardiomyopathy: pathophysiology and evolution of the clinical syndrome," American Journal of the Medical Sciences, vol. 321, no. 4, pp. 225-236, 2001.

[58] B. D. Powell, M. M. Redfield, K. A. Bybee, W. K. Freeman, and C. S. Rihal, "Association of obesity with left ventricular remodeling and diastolic dysfunction in patients without coronary artery disease," American Journal of Cardiology, vol. 98, no. 1, pp. 116-120, 2006.

[59] L. R. Peterson, A. D. Waggoner, K. B. Schechtman et al., "Alterations in left ventricular structure and function in young healthy obese women: assessment by echocardiography and tissue Doppler imaging," Journal of the American College of Cardiology, vol. 43, no. 8, pp. 1399-1404, 2004.

[60] A. Wirth and H. Kroger, "Improvement of left ventricular morphology and function in obese subjects following a diet and exercise program," International Journal of Obesity, vol. 19, no. 1, pp. 61-66, 1995.

[61] C. Y. Wong, N. M. Byrne, T. O’Moore-Sullivan, A. P. Hills, J. B. Prins, and T. H. Marwick, "Effect of weight loss due to lifestyle intervention on subclinical cardiovascular dysfunction in obesity (body mass index $>30 \mathrm{~kg} / \mathrm{m} 2$ )," American Journal of Cardiology, vol. 98, no. 12, pp. 1593-1598, 2006.

[62] V. Pengo, A. W. Lensing, M. H. Prins et al., "Incidence of chronic thromboembolic pulmonary hypertension after pulmonary embolism," The New England Journal of Medicine, vol. 350, no. 22, pp. 2257-2264, 2004.

[63] V. F. Tapson, H. Decousus, M. Pini et al., "Venous thromboembolism prophylaxis in acutely ill hospitalized medical patients: findings from the International Medical Prevention Registry on Venous Thromboembolism," Chest, vol. 132, no. 3, pp. 936-945, 2007.

[64] S. Z. Goldhaber, "Epidemiology of pulmonary embolism," Seminars in Vascular Medicine, vol. 1, no. 2, pp. 139-146, 2001.

[65] S. Z. Goldhaber, D. D. Savage, R. J. Garrison et al., "Risk factors for pulmonary embolism. The Framingham Study," American Journal of Medicine, vol. 74, no. 6, pp. 1023-1028, 1983.

[66] M. R. Movahed, M. Hashemzadeh, and M. M. Jamal, "The prevalence of pulmonary embolism and pulmonary hypertension in patients with type II diabetes mellitus," Chest, vol. 128, no. 5, pp. 3568-3571, 2005.

[67] G. Bokinsky, M. Miller, K. Ault, P. Husband, and J. Mitchell, "Spontaneous platelet activation and aggregation during obstructive sleep apnea and its response to therapy with nasal continuous positive airway pressure: a preliminary investigation," Chest, vol. 108, no. 3, pp. 625-630, 1995.

[68] C. Rangemark, J. A. Hedner, J. T. Carlson, G. Gleerup, and K. Winther, "Platelet function and fibrinolytic activity in 
hypertensive and normotensive sleep apnea patients," Sleep, vol. 18, no. 3, pp. 188-194, 1995.

[69] R. D. Rosenberg and W. C. Aird, "Vascular-bed-specific hemo stasis and hypercoagulable states," The New England Journal of Medicine, vol. 340, no. 20, pp. 1555-1564, 1999.

[70] R. T. Zamanian, G. Hansmann, S. Snook et al., "Insulin resistance in pulmonary arterial hypertension," European Respiratory Journal, vol. 33, no. 2, pp. 318-324, 2009.

[71] B. Fouty, "Diabetes and the pulmonary circulation," American Journal of Physiology, vol. 295, no. 5, pp. L725-L726, 2008.

[72] J. T. Carlson, C. Rångemark, and J. A. Hedner, "Attenuated endothelium-dependent vascular relaxation in patients with sleep apnoea," Journal of Hypertension, vol. 14, no. 5, pp. 577 $584,1996$.

[73] A. T. Murugan and G. Sharma, "Obesity and respiratory diseases," Chronic Respiratory Disease, vol. 5, no. 4, pp. 233-242, 2008.

[74] K. Ramar and S. M. Caples, "Vascular changes, cardiovascular disease and obstructive sleep apnea," Future Cardiology, vol. 7, no. 2, pp. 241-249, 2011.

[75] J. G. Lopez-Lopez, J. Moral-Sanz, G. Frazziano et al., "Type 1 diabetes-induced hyper-responsiveness to 5-hydroxytryptamine in rat pulmonary arteries via oxidative stress and induction of cyclooxygenase-2," Journal of Pharmacology and Experimental Therapeutics, vol. 338, no. 1, pp. 400-407, 2011.

[76] J. Moral-Sanz, C. Menendez, L. Moreno, E. Moreno, A. Cogolludo, and F. Perez-Vizcaino, "Pulmonary arterial dysfunction in insulin resistant obese Zucker rats," Respiratory Research, vol. 12, article 51, 2011.

[77] J. G. Lopez-Lopez, J. Moral-Sanz, G. Frazziano et al., "Diabetes induces pulmonary artery endothelial dysfunction by NADPH oxidase induction," American Journal of Physiology, vol. 295, no. 5, pp. L727-L732, 2008.

[78] J. Moral-Sanz, J. G. Lopez-Lopez, C. Menendez et al., "Different patterns of pulmonary vascular disease induced by type 1 diabetes and moderate hypoxia in rats," Experimental Physiology, vol. 97, no. 5, pp. 676-686, 2012.

[79] J. T. Crossno Jr., C. V. Garat, J. E. Reusch et al., "Rosiglitazone attenuates hypoxia-induced pulmonary arterial remodeling," American Journal of Physiology, vol. 292, no. 4, pp. L885-L897, 2007.

[80] G. Hansmann, R. A. Wagner, S. Schellong et al., "Pulmonary arterial hypertension is linked to insulin resistance and reversed by peroxisome proliferator-activated receptor- $\gamma$ activation," Circulation, vol. 115, no. 10, pp. 1275-1284, 2007.

[81] M. Alchanatis, G. Tourkohoriti, S. Kakouros, E. Kosmas, S. Podaras, and J. B. Jordanoglou, "Daytime pulmonary hypertension in patients with obstructive sleep apnea: the effect of continuous positive airway pressure on pulmonary hemodynamics," Respiration, vol. 68, no. 6, pp. 566-572, 2001.

[82] R. Wolk, T. Kara, and V. K. Somers, "Sleep-disordered breathing and cardiovascular disease," Circulation, vol. 108, no. 1, pp. 9-12, 2003.

[83] J. Joya-Galeana, M. Fernandez, A. Cervera et al., "Effects of insulin and oral anti-diabetic agents on glucose metabolism, vascular dysfunction and skeletal muscle inflammation in type 2 diabetic subjects," Diabetes/Metabolism Research and Reviews, vol. 27, no. 4, pp. 373-382, 2011.

[84] H. Kitahara, Y. Kobayashi, Y. Iwata, Y. Fujimoto, and I. Komuro, "Effect of pioglitazone on endothelial dysfunction after sirolimus-eluting stent implantation," American Journal of Cardiology, vol. 108, no. 2, pp. 214-219, 2011.

[85] K. K. Naka, K. Papathanassiou, A. Bechlioulis et al., "Rosiglitazone improves endothelial function in patients with type 2 diabetes treated with insulin," Diabetes and Vascular Disease Research, vol. 8, no. 3, pp. 195-201, 2011.

[86] S. Azhar, "Peroxisome proliferator-activated receptors, metabolic syndrome and cardiovascular disease," Future Cardiology, vol. 6, no. 5, pp. 657-691, 2010.

[87] M. A. Voelkel, K. M. Wynne, D. B. Badesch, B. M. Groves, and N. F. Voelkel, "Hyperuricemia in severe pulmonary hypertension," Chest, vol. 117, no. 1, pp. 19-24, 2000.

[88] S. I. Zharikov, E. R. Swenson, M. Lanaspa, E. R. Block, J. M. Patel, and R. J. Johnson, "Could uric acid be a modifiable risk factor in subjects with pulmonary hypertension?" Medical Hypotheses, vol. 74, no. 6, pp. 1069-1074, 2010.

[89] G. Mercuro, C. Vitale, E. Cerquetani et al., "Effect of hyperuricemia upon endothelial function in patients at increased cardiovascular risk," American Journal of Cardiology, vol. 94, no. 7, pp. 932-935, 2004.

[90] S. Zharikov, K. Krotova, H. Hu et al., "Uric acid decreases NO production and increases arginase activity in cultured pulmonary artery endothelial cells," American Journal of Physiology, vol. 295, no. 5, pp. C1183-C1190, 2008.

[91] R. J. Barst, J. S. Gibbs, H. A. Ghofrani et al., "Updated evidence-based treatment algorithm in pulmonary arterial hypertension," Journal of the American College of Cardiology, vol. 54, no. 1, supplement, pp. S78-S84, 2009.

[92] R. J. Barst, L. J. Rubin, W. A. Long et al., "A comparison of continuous intravenous epoprostenol (prostacyclin) with conventional therapy for primary pulmonary hypertension," The New England Journal of Medicine, vol. 334, no. 5, pp. 296-302, 1996.

[93] M. M. Hoeper, J. A. Barberà, R. N. Channick et al., "Diagnosis, assessment, and treatment of non-pulmonary arterial hypertension pulmonary hypertension," Journal of the American College of Cardiology, vol. 54, no. 1, supplement, pp. S85-S96, 2009.

[94] M. Guazzi, M. Vicenzi, R. Arena, and M. D. Guazzi, "Pulmonary hypertension in heart failure with preserved ejection fraction: a target of phosphodiesterase- 5 inhibition in a 1-year study," Circulation, vol. 124, no. 2, pp. 164-174, 2011.

[95] C. J. Archibald, W. R. Auger, P. F. Fedullo et al., "Long-term outcome after pulmonary thromboendarterectomy," American Journal of Respiratory and Critical Care Medicine, vol. 160, no. 2, pp. 523-528, 1999. 


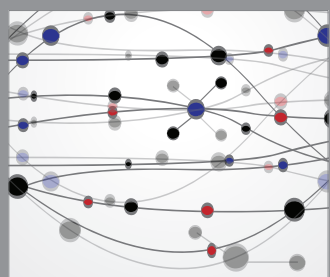

The Scientific World Journal
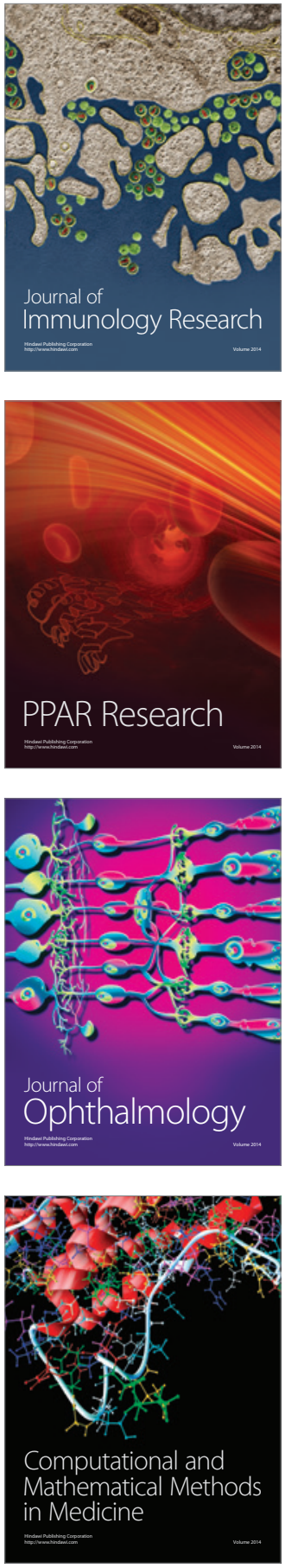

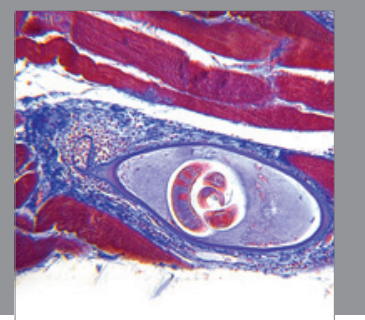

Gastroenterology

Research and Practice
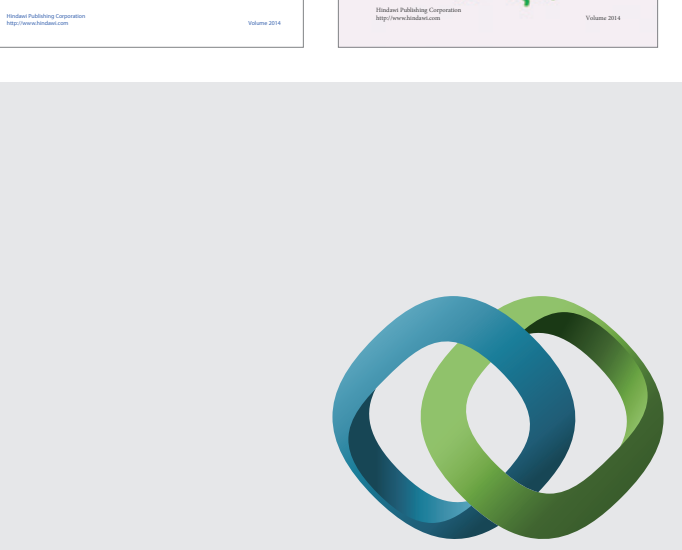

\section{Hindawi}

Submit your manuscripts at

http://www.hindawi.com
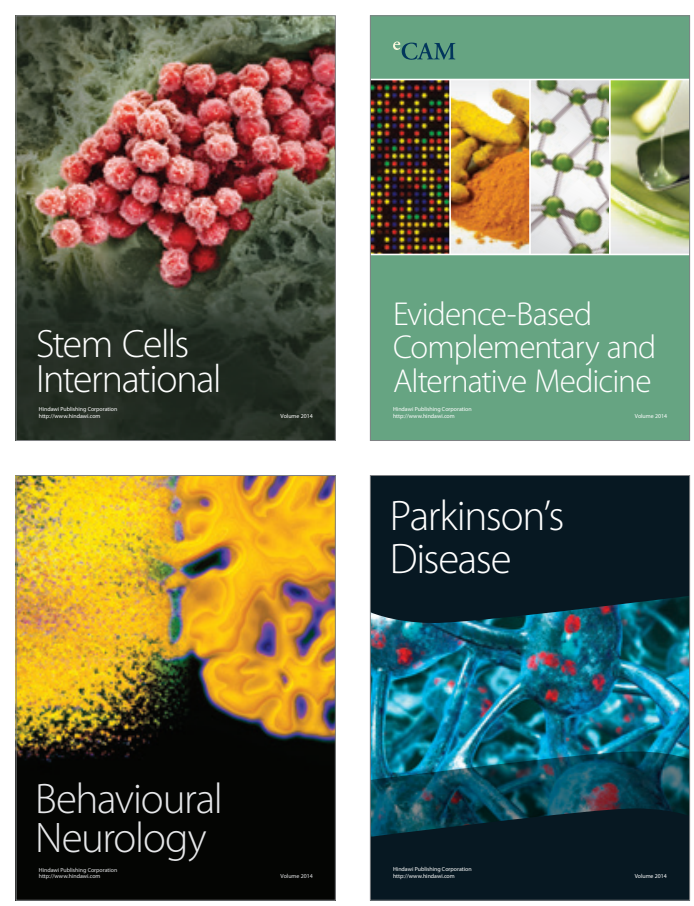

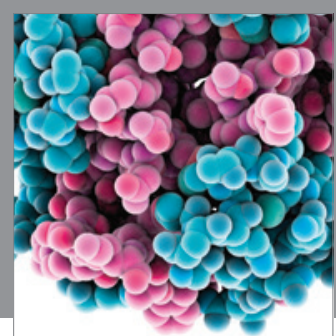

Journal of
Diabetes Research

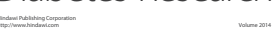

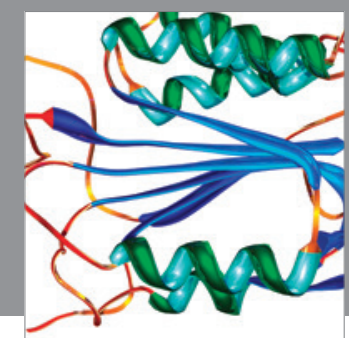

Disease Markers
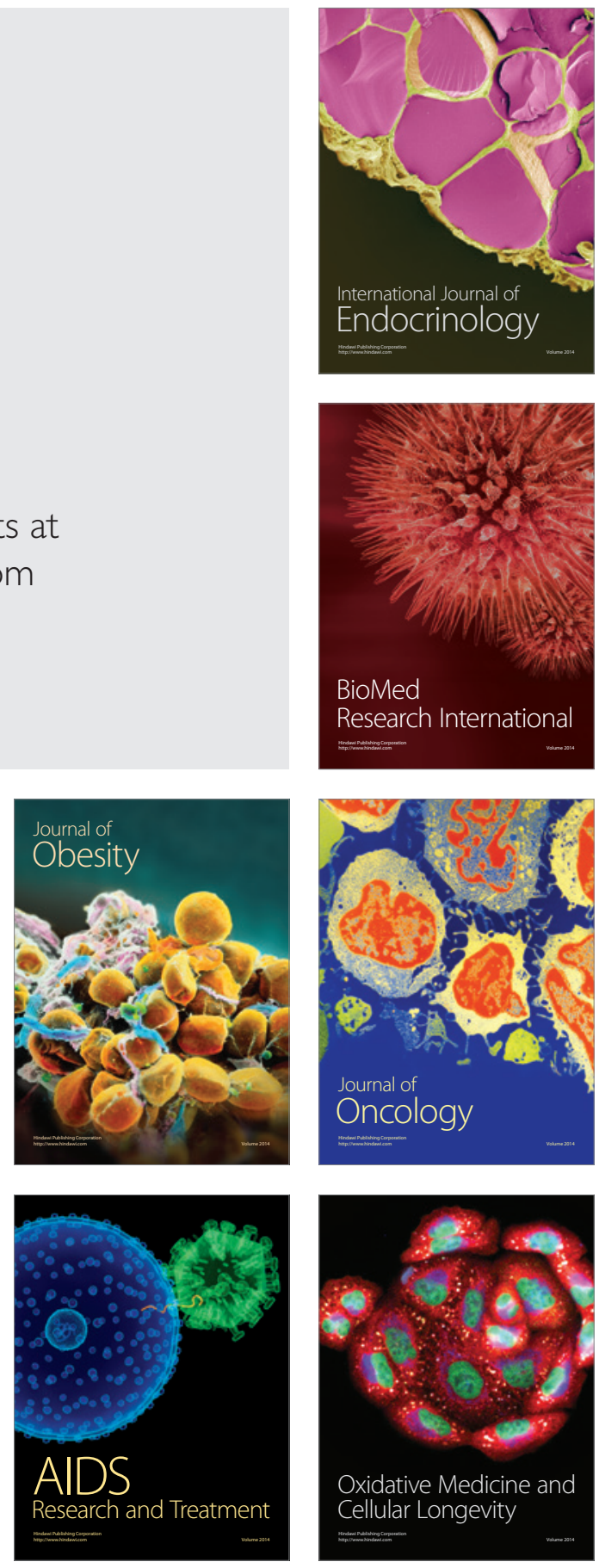